\title{
Prevalensi Konstipasi Pada Ibu Hamil
}

\section{Prevalence of Constipation in Pregnant Women}

\author{
Fransisca Retno Asih \\ Program Studi Kebidanan STIKes Banyuwangi \\ Email: davisaputra90@gmail.com
}

\begin{abstract}
ABSTRAK
Konstipasi merupakan keluhan pada sistem gastrointestinal yang umum dialami oleh ibu hamil, dapat memengaruhi kesehatan fisik, psikologis, sosial, serta kualitas hidup. Belum ada penelitian terkait prevalensi konstipasi kehamilan di Banyuwangi. Penelitian ini bertujuan untuk memberikan gambaran umum tentang prevalensi konstipasi pada ibu hamil berdasarkan kriteria Roma II. Metode penelitian ini adalah deskriptif dengan pendekatan cross sectional pada 715 ibu hamil usia kehamilan 13-16 minggu, 27-30 minggu, dan 36-39 minggu, kehamilan tunggal, dan bersedia menjadi responden penelitian di lima Puskesmas di Banyuwangi. Ibu hamil yang memenuhi kriteria dan datang ke Puskesmas secara berurutan (consecutive sampling) diberi kuesioner yang berisi tujuh pertanyaan tentang gejala konstipasi sesuai kriteria Roma II. Hasil penelitian yaitu 17,8\% dari 715 ibu hamil mengalami konstipasi. Prevalensi konstipasi pada trimester III (19,3\%) lebih tinggi dibandingkan dengan trimester I (17,3\%) dan II $(16,4 \%)$. Ibu hamil yang bekerja, berpendidikan tinggi, dan primigravida menunjukkan prevalensi konstipasi yang lebih tinggi. Simpulan penelitian yaitu konstipasi pada semua trimester kehamilan sebagian besar ditandai dengan konsistensi tinja keras dan mengejan kuat pada lebih dari satu kali dalam empat kali defekasi selama empat minggu. Skrining dan konseling konstipasi penting dilakukan oleh Bidan pada kontak awal kehamilan khususnya di fasilitas kesehatan tingkat pertama.
\end{abstract}

Kata Kunci: Konstipasi, Ibu Hamil

\begin{abstract}
Constipation is a complaint of the gastrointestinal system that is commonly experienced by pregnant women, which can affect physical, psychological, social health, and quality of life. There has been no research related to the prevalence of pregnancy constipation in Banyuwangi. This study aims to provide an overview of the prevalence of constipation in pregnant women based on the Rome II criteria. This research method was descriptive with a cross sectional approach to 715 pregnant women with gestational age of 13-16 weeks, 27-30 weeks, and 36-39 weeks, singleton pregnancies, and became research respondents in five primary health care facilities in Banyuwangi. Pregnant women who met the criteria and came to the primary health care facilities sequentially (consecutive sampling) were given a questionnaire containing seven questions about symptoms of constipation according to the Rome II criteria. The results of the study were $17.8 \%$ of 715 pregnant women were constipated. The prevalence of constipation in the third trimester (19.3\%) was higher than in the first (17.3\%) and second trimester (16.4\%). Pregnant women who are working, highly educated, and primigravida show a higher prevalence of constipation. The conclusion of the study is that constipation in all trimesters of large pregnancy is characterized by the consistency of hard and strong stools at one time in four defecations for four weeks. Constipation screening and counseling is important for midwives at the initial contact, especially in first-level of health facilities.
\end{abstract}

Keywords: Constipation, Pregnant Women

\section{PENDAHULUAN}

Konstipasi merupakan keluhan

sistem gastrointestinal yang umum dialami oleh ibu hamil. Kesulitan dan berkurangnya frekuensi defekasi yang

ditandai dengan ketidaknyamanan, 
mengejan berlebihan, feses keras atau menggumpal, sensasi defekasi yang tidak tuntas, dan jarang merupakan karakteristik dari konstipasi (Shin, Toto and Schey, 2015).

Konstipasi pada kehamilan berdampak pada kesehatan fisik, psikologis, dan sosial yaitu menyebabkan rasa tidak nyaman, persepsi citra tubuh yang negatif, gangguan psikologis seperti rasa frustasi dan suasana hati yang buruk, menurunkan kualitas hidup, dan bahkan meningkatkan risiko terjadinya hemoroid (Johnson, Mount and Graziano, 2014). Selain itu, ibu hamil dengan konstipasi berisiko lebih tinggi mengalami persalinan secara seksio sesarea, defekasi pertama setelah melahirkan yang lebih lambat, dan hemoroid postpartum dibandingkan dengan yang tidak mengalami konstipasi (Shi et al., 2015).

Prevalensi konstipasi di Indonesia yaitu $12,9 \%$ lebih rendah dibandingkan dengan China dan Korea Selatan (15,2\% dan 16,7\%). Dari $12,9 \%$, prevalensi konstipasi di Indonesia pada perempuan lebih tinggi $(15,1 \%)$ dibandingkan dengan laki-laki $(10,7 \%)$. Hasil penelitian di beberapa negara, prevalensi konstipasi tidak berkaitan dengan letak geografis dan budaya (Wald et al., 2010). Pada kehamilan, prevalensi konstipasi bervariasi antara $11-44 \%$ (Bradley et al., 2007) (Trottier, Erebara and Bozzo, 2012) (Rungsiprakarn et al., 2015).

Prevalensi konstipasi pada kehamilan telah diketahui, namun penelitian terkait prevalensi dan gambaran umum konstipasi pada kehamilan di Indonesia masih terbatas khususnya di Banyuwangi. Penelitian ini bertujuan untuk memberikan gambaran umum tentang prevalensi konstipasi dan karakteristik keluhan konstipasi pada ibu hamil di Banyuwangi berdasarkan kriteria Roma II.

\section{METODE PENELITIAN}

Penelitian deskriptif dengan pendekatan cross sectional ini dilakukan di lima Puskesmas di Banyuwangi. Penelitian ini telah lolos kaji etik dari Komisi Etik Penelitian Kesehatan Sekolah Tinggi Ilmu Kesehatan Banyuwangi (No. 536/KEPK/STIKES-BWI) pada $10 \mathrm{Mei}$ 2021 dan mendapatkan persetujuan dari instansi terkait (PPPM STIKes Banyuwangi, Dinas Penanaman Modal dan Pelayanan Terpadu Satu Pintu 
Banyuwangi, dan Dinas Kesehatan Banyuwangi) serta informed consent dari setiap subjek penelitian.

Populasi target penelitian ini adalah semua ibu hamil di wilayah Banyuwangi sedangkan populasi terjangkau adalah semua ibu hamil di lima Puskesmas di Banyuwangi. Teknik pengambilan sampel secara consecutive yaitu setiap ibu hamil yang datang ke lima Puskesmas di Banyuwangi secara berurutan pada periode Juni hingga November 2021 dan telah lolos seleksi berdasarkan kriteria inklusi dan eksklusi, masuk sebagai subjek penelitian.

Kriteria inklusi penelitian ini adalah ibu hamil pada setiap akhir trimester kehamilan (13-16 minggu, 2730 minggu, dan 36-39 minggu), kehamilan tunggal, dan bersedia menjadi subjek penelitian. Ibu hamil dengan disabilitas berupa tuna wicara dan tuna rungu menjadi kriteria eksklusi penelitian. Sebanyak 715 ibu hamil menjadi sampel atau subjek penelitian ini.

Kuesioner penelitian berupa tujuh pertanyaan kriteria diagnosis konstipasi fungsional berdasarkan kriteria Roma II yang telah dimodifikasi untuk digunakan pada kehamilan.
Adapun kriteria Roma II antara lain: 1) mengejan kuat pada lebih dari satu kali dalam empat kali defekasi; 2) konsistensi tinja keras pada lebih dari satu kali dalam empat kali defekasi; 3) sensasi pengeluaran tinja yang tidak komplit lebih dari satu kali dalam empat kali defekasi; 4) sensasi sumbatan atau obstruksi pada lebih dari satu kali dalam empat kali defekasi; 5) adanya tindakan manual lebih dari satu kali dalam empat kali defekasi; 6) frekuensi defekasi kurang dari tiga kali seminggu; dan 7) defekasi tanpa disertai tinja cair dan tidak memenuhi kriteria irritable bowel syndrome. Apabila keluhan dirasakan selama empat minggu atau satu bulan dan memenuhi dua atau lebih kriteria, maka dinyatakan mengalami konstipasi. Karakteristik seperti usia, pendidikan, pekerjaan, status gravida, dan usia kehamilan ditanyakan melalui kuesioner penelitian.

Pengumpulan data dan identifikasi konstipasi dilakukan oleh enumerator yaitu Bidan di lima Puskesmas yang sebelumnya telah mendapatkan pengarahan dari peneliti. Peneliti menyediakan dua macam media pengumpulan data yaitu media cetak berupa hardcopy kuesioner dan elektronik berupa google form. Data 
dari kuesioner yang telah terkumpul dianalisis secara univariate berupa tabel frekuensi serta persentase.

\section{HASIL DAN PEMBAHASAN}

Tabel 1. Distribusi 715 sampel

\begin{tabular}{lc}
\hline \multicolumn{1}{c}{ Karakteristik } & $\mathrm{n}(\%), \mathrm{N}=715$ \\
\hline Usia (tahun) & \\
$-\quad<20$ & $43(6)$ \\
$-\quad 20-25$ & $243(34)$ \\
$-\quad 26-30$ & $215(30,1)$ \\
$-\quad 31-35$ & $151(21,2)$ \\
$-\quad 36-40$ & $58(8,1)$ \\
$-\quad>40$ & $5(0,7)$ \\
Pendidikan & \\
$-\quad$ SD/SMP & $230(32,2)$ \\
$-\quad$ SMA & $380(53,1)$ \\
$-\quad$ PT & $105(14,7)$ \\
Pekerjaan & \\
$-\quad$ Bekerja & $167(23,4)$ \\
$-\quad$ Tidak bekerja & $548(76,6)$ \\
Gravida & \\
$-\quad$ Primigravida & $264(36,9)$ \\
$-\quad$ Multigravida & $451(63,1)$ \\
Usia kehamilan (minggu) & \\
$-\quad$ 13-16 & $266(37,2)$ \\
$-\quad 27-30$ & $195(27,3)$ \\
$-\quad 36-39$ & $254(35,5)$ \\
\hline
\end{tabular}

Jumlah subjek penelitian yaitu 715 ibu hamil dengan rentang dari usia 16 hingga 40 tahun. Usia rata-rata (standar deviasi) adalah $27(5,77)$ tahun dan median usia adalah 27 tahun. 6\% subjek penelitian berusia $<20$ tahun dan $8,8 \%$ berusia $>35$ tahun. Sebagian besar subjek tidak bekerja (76,6\%). Karakteristik seluruh subjek penelitian ditunjukkan pada Tabel 1.

Prevalensi konstipasi pada ibu hamil adalah 17,8\% atau 127 dari 715 ibu hamil (Tabel 2). Tabel 2 menunjukkan tentang distribusi rinci dari karakteristik umum dan keluhan (berdasarkan kriteria Roma II) pada subjek penelitian dengan konstipasi serta prevalensi konstipasi berdasarkan karakteristik ibu hamil.

Tabel 2. Karakteristik umum dan prevalensi konstipasi

\begin{tabular}{|c|c|c|}
\hline Karakteristik & $\begin{array}{c}\mathrm{n}(\%) \\
\mathrm{N}=127\end{array}$ & $\begin{array}{c}\text { Preva } \\
\text { lensi* } \\
(\%)\end{array}$ \\
\hline \multicolumn{3}{|l|}{ Karakteristik umum } \\
\hline \multicolumn{3}{|l|}{ Usia (tahun) } \\
\hline$-\quad<20$ & $8(6,3)$ & 18,6 \\
\hline$-\quad 20-25$ & $46(36,2)$ & 18,9 \\
\hline$-\quad 26-30$ & $35(27,6)$ & 16,3 \\
\hline$-\quad 31-35$ & $29(22,8)$ & 19,2 \\
\hline$-\quad 36-40$ & $7(5,5)$ & 12,1 \\
\hline$-\quad>40$ & $2(1,6)$ & 40 \\
\hline \multicolumn{3}{|l|}{ Pendidikan } \\
\hline - $\quad$ SD/SMP & $34(26,8)$ & 14,8 \\
\hline - $\quad$ SMA & $66(51,9)$ & 17,4 \\
\hline PT & $27(21,3)$ & 25,7 \\
\hline \multicolumn{3}{|l|}{ Pekerjaan } \\
\hline - Bekerja & $35(27,6)$ & 20,9 \\
\hline - $\quad$ Tidak bekerja & $92(72,4)$ & 16,8 \\
\hline \multicolumn{3}{|l|}{ Gravida } \\
\hline - $\quad$ Primigravida & $56(44,1)$ & 21,2 \\
\hline Multigravida & $71(55,9)$ & 15,7 \\
\hline \multicolumn{3}{|l|}{ Usia kehamilan } \\
\hline - $\quad 13-16$ minggu & $46(36,2)$ & 17,3 \\
\hline 27-30 minggu & $32(25,2)$ & 16,4 \\
\hline - $\quad 36-39$ minggu & $49(38,6)$ & 19,3 \\
\hline
\end{tabular}

Dari 71 multigravida, 49,3\% merupakan kehamilan kedua, 39,4\% kehamilan ketiga, dan 5,6\% kehamilan keempat, 1,4\% kehamilan kelima, dan 4,2\% kehamilan lebih dari lima. Prevalensi konstipasi pada kehamilan berdasarkan usia kehamilan atau trimester berturut-turut dari yang terbesar yaitu trimester I, trimester III, dan trimester II dengan perbedaan 
selisih persentase kurang dari 5\%

(Tabel 2). Ibu hamil trimester III dengan konstipasi lebih sering mengalami konsistensi tinja keras, gejala mengejan kuat, dan sensasi mengeluarkan tinja tidak komplit saat defekasi (Tabel 3).

Tabel 3. Karakteristik Keluhan Konstipasi

\begin{tabular}{|c|c|c|c|}
\hline $\begin{array}{c}\text { Karakteristik } \\
\text { keluhan }\end{array}$ & $\begin{array}{c}\text { TM I } \\
(\mathrm{n}=46) \\
(\%)\end{array}$ & $\begin{array}{c}\text { TM II } \\
(\mathrm{n}=32) \\
(\%)\end{array}$ & $\begin{array}{c}\text { TM III } \\
(\mathrm{n}=49) \\
(\%)\end{array}$ \\
\hline - Mengejan kuat & $25(54)$ & $19(59)$ & $30(61)$ \\
\hline $\begin{array}{l}\text { - Konsistensi tinja } \\
\text { keras }\end{array}$ & $24(52)$ & $21(65)$ & $31(63)$ \\
\hline $\begin{array}{l}\text { - Sensasi } \\
\text { pengeluaran tinja } \\
\text { tidak komplit }\end{array}$ & $20(43)$ & $15(46)$ & $25(51)$ \\
\hline $\begin{array}{l}\text { - Sensasi sumbatan } \\
\text { atau obstruksi }\end{array}$ & $21(45)$ & $11(34)$ & $19(38)$ \\
\hline $\begin{array}{l}\text { - Adanya tindakan } \\
\text { manual }\end{array}$ & $9(19)$ & $5(15)$ & $5(10)$ \\
\hline $\begin{array}{l}\text { - Frekuensi } \\
\text { defekasi kurang } \\
\text { dari tiga kali } \\
\text { seminggu }\end{array}$ & $22(47)$ & $8(25)$ & $16(32)$ \\
\hline $\begin{array}{l}\text { - Defekasi tanpa } \\
\text { disertai tinja cair } \\
\text { dan tidak } \\
\text { memenuhi } \\
\text { kriteria irritable } \\
\text { bowel syndrome }\end{array}$ & $19(41)$ & $18(56)$ & $9(18)$ \\
\hline
\end{tabular}

Prevalensi konstipasi kehamilan berdasarkan kriteria Roma II pada penelitian ini adalah $17,8 \%$ dengan rentang 16,4-19,3\% menurut trimester kehamilan. Hasil ini lebih rendah dibandingkan dengan penelitian Bradley dan Ponce yang juga menggunakan kriteria Roma II yaitu 16-26\% (Bradley et al., 2007) dan 19-29,6\% (Ponce et al., 2008).
Penelitian yang dilakukan Shi, dkk di tiga rumah sakit di Shanghai, China menunjukkan bahwa dari 1698 ibu hamil, 13,01\% (221 ibu hamil) mengalami konstipasi fungsional berdasarkan kriteria Roma III atau lebih rendah dibandingkan dengan kriteria Roma II pada hasil penelitian ini (Shi et $a l ., 2015)$. Hal ini disebabkan adanya perbedaan lama waktu dalam mengidentifikasi konstipasi juga desain penelitian yang digunakan. Pada kriteria Roma III, jangka waktu identifikasi konstipasi adalah dua belas minggu, lebih panjang dibandingkan dengan kriteria Roma II yaitu empat minggu atau satu bulan (Shi et al., 2015).

Prevalensi konstipasi berdasarkan pengelompokan tingkat pendidikan paling besar pada kelompok pendidikan tinggi sedangkan berdasarkan status pekerjaan paling besar pada kelompok ibu hamil yang bekerja (Tabel 1 dan 2). Hal ini sejalan dengan hasil penelitian Shi,dkk dan Ponce, dkk yaitu prevalensi konstipasi paling besar terjadi pada ibu hamil yang berpendidikan tinggi dan bekerja (Shi et al., 2015) (Ponce et al., 2008).

Prevalensi tertinggi pada penelitian ini terjadi pada trimester III $(19,3 \%)$ berbeda dengan Ponce, dkk 
yaitu pada trimester I $(29,6 \%)$ (Ponce $e t$ al., 2008) sedangkan menurut Bradley, dkk persentase tertinggi pada trimester II (26\%). Namun, perbedaan prevalensi konstipasi antar trimester pada ketiga penelitian tersebut tidak berbeda jauh atau hampir sama. Hal ini didukung dengan perubahan fisiologis khususnya peningkatan hormone kehamilan yaitu progesteron.

Hormon progesteron bekerja dengan cara mengendurkan otot polos sehingga uterus dalam kondisi tenang dan kontraksi uterus premature dapat dicegah. Peningkatan hormon progesteron memengaruhi fungsi sfingter anal dan menurunkan motilitas lambung dan usus sehingga waktu pengosongan lambung menjadi lebih lama. Selain itu, efek tekan dari rahim yang membesar seiring pertumbuhan janin menyebabkan obstruksi mekanis pada usus (Shin, Toto and Schey, 2015). Hal tersebut yang menjadi penyebab konstipasi pada kehamilan, meskipun terdapat juga beberapa faktor penyebab lainnya, pola makan dan asupan cairan yang buruk, penurunan aktivitas ibu, suplementasi zat besi, riwayat konstipasi sebelumnya, kecemasan, dan posisi defekasi (Rungsiprakarn et al., 2015) (Sembiring, 2017).
Kekuatan penelitian ini adalah banyak sampel yang cukup besar, sehingga hasil penelitian ini dapat mewakili seluruh populasi ibu hamil di Indonesia khususnya di Banyuwangi. Namun, terdapat keterbatasan pada penelitian ini yaitu gambaran umum terkait karakteristik penyebab konstipasi seperti riwayat konstipasi, pola aktivitas, pola posisi defekasi, pola nutrisi dan asupan cairan, suplementasi zat besi, riwayat hasil pemeriksaan kadar $\mathrm{Hb}$ pada ANC Terpadu, dan identifikasi adanya gangguan kecemasan, tidak dikaji oleh peneliti. Pada penelitian selanjutnya, selain ukuran sampel yang cukup, diperlukan pengkajian atau survei tentang gambaran atau karakteristik atau faktor risiko konstipasi pada kehamilan secara lebih lengkap serta desain penelitian dan tempat penelitian yang berbeda.

\section{SIMPULAN DAN SARAN}

Dapat disimpulkan bahwa konstipasi merupakan keluhan yang umum terjadi pada semua trimester kehamilan yang sebagian besar ditandai dengan konsistensi tinja keras dan mengejan kuat pada lebih dari satu kali dalam empat kali defekasi selama empat minggu. Berdasarkan temuan ini, 
peneliti menyarankan perlunya skrining dan konseling terkait keluhan konstipasi pada kontak awal kehamilan khususnya di fasilitas kesehatan tingkat pertama (FKTP) sebagai langkah awal dalam upaya promotif dan preventif yang sesuai dengan standar asuhan kebidanan.

Peneliti menyatakan bahwa tidak ada konflik kepentingan dalam penelitian ini. Pada proses pengumpulan data penelitian, peneliti telah dibantu oleh enumerator sehingga peneliti menyampaikan terima kasih atas kerja sama dan dukungan kepada para Bidan dari lima Puskesmas di Banyuwangi yaitu Bidan Henny (Puskesmas Klatak), Bidan Wiwik (Puskesmas Kabat), Bidan Iptitah (Puskesmas Gitik), Bidan Siti (Puskesmas Benculuk), dan Bidan Titin (Puskesmas Genteng Kulon).

\section{DAFTAR PUSTAKA}

Bradley, C. S. et al. (2007) 'Constipation in pregnancy: prevalence, symptoms, and risk factors.', Obstetrics and gynecology, 110(6), pp. 1351$1357 . \quad$ doi: 10.1097/01.AOG.0000295723.9 4624.b1.

Johnson, P., Mount, K. and Graziano, S. (2014) 'Functional bowel disorders in pregnancy: Effect on quality of life, evaluation and management', Acta Obstetricia et Gynecologica Scandinavica, 93(9), pp. 874-879. doi: 10.1111/aogs.12434.

Ponce, J. et al. (2008) 'Constipation during pregnancy: a longitudinal survey based on self-reported symptoms and the Rome II criteria.', European journal of gastroenterology \& hepatology, 20(1), pp. 56-61. doi: 10.1097/MEG.0b013e32811080 58.

Rungsiprakarn, P. et al. (2015) 'Interventions for treating constipation in pregnancy', Cochrane Database of Systematic Reviews, 2015(9). doi: 10.1002/14651858.CD011448.p $\mathrm{ub} 2$.

Sembiring, L. P. (2017) 'Konstipasi pada Kehamilan', Jurnal Ilmu Kedokteran, 9(1), p. 7. doi: 10.26891/jik.v9i1.2015.7-10.

Shi, W. et al. (2015) 'Epidemiology and risk factors of functional constipation in pregnant women', PLoS ONE, 10(7), pp. $1-10$. doi: 10.1371/journal.pone.0133521.

Shin, G. H., Toto, E. L. and Schey, R. (2015) 'Pregnancy and postpartum bowel changes: Constipation and fecal incontinence', American Journal of Gastroenterology, 110(4), pp. 521-529. doi: 10.1038/ajg.2015.76.

Trottier, M., Erebara, A. and Bozzo, P. (2012) 'Treating constipation during pregnancy', Canadian Family Physician, 58(8), p. 836. 
66 Oksitosin: Jurnal Ilmiah Kebidanan, Vol. 9, No. 1, Februari 2022: 59-66

Wald, A. et al. (2010) 'Survey of laxative use by adults with selfdefined constipation in South America and Asia: A comparison of six countries',
Alimentary Pharmacology and Therapeutics, 31(2), pp. 274284. doi: $10.1111 / \mathrm{j} .1365-$ 2036.2009.04169.x. 